\title{
The Analysis of Meteorological Conditions for Icing on UHV Transmission Lines in Southeast Guizhou in 2018
}

\author{
Hourong Zhang ${ }^{1, \text { a }}$, Shiqi Zhang ${ }^{2}$, Qi Wang ${ }^{1, *}$, and Hao Chai ${ }^{1}$ \\ ${ }^{1}$ Maintenance \& Test Center of CSG EHV Power Transmission Company, Guangzhou 510663, China \\ ${ }^{2}$ School of Atmospheric Physics, Nanjing University of Information Science and Technology, Nanjing, 210044, China
}

\begin{abstract}
Using ERA5 reanalysis data of ECMWF and the ultra-high voltage (UHV) transmission line icing observation system to analyze the meteorological conditions of conductor icing in Guizhou from January 24 to 29, 2018, Results show: The weather conditions for this icing event are that the temperature drops below $0^{\circ} \mathrm{C}$, there is weak rainfall, and the humidity is generally between $95 \%$ and $100 \%$; the direction is mainly northerly wind, with wind speed of $2 \sim 6 \mathrm{~m} / \mathrm{s}$; the air pressure rises. The meteorological elements that are more relevant to icing are environmental temperature, air pressure, and precipitation. The relationship with wind speed and relative humidity is small.
\end{abstract}

\section{Introduction}

In recent years, the frequent occurrence of meteorological disasters has seriously threatened the safe operation of power grids. Among them, conductor icing is one of the important issues affecting the safe operation of the power grid. The phenomenon of conductor icing is common at home and abroad, and China is one of the countries with the most severe conductor icing in the world ${ }^{[1-5]}$. The mechanism of conductor icing under natural conditions is very complicated, and there are many factors that affect icing, including meteorological factors, terrain factors and wire characteristics. Meteorological conditions are the most important factor and have a decisive influence ${ }^{[6]}$.

At present, there have been many researches on the meteorological conditions of severely icing areas: Tao Yun et al. ${ }^{[7]}$ analyzed the meteorological conditions of the severe conductor icing disaster that occurred in northeastern Yunnan in the winter of 2008, and believed that the conductor icing phenomenon this time occurred under the weather conditions of low temperature, low precipitation, low wind speed or quiet wind and relatively humid air. Huang Haohui and others ${ }^{[4]}$ indicated that the main meteorological factors affecting the icing thickness were low temperature, near-saturated relative humidity, a certain amount of precipitation, and appropriate wind speed. Qin Wu et al. ${ }^{[8]}$ pointed out that the meteorological conditions for conductor icing in Guangxi are: low temperature and low sunshine, wind speed $<5 \mathrm{~m} / \mathrm{s}$, mainly northerly wind, weak precipitation, and drizzle is the most favorable.

In recent years, the phenomenon of icing in Guizhou still exists, especially the intensity of icing in 2018 is particularly serious. During this period, the icing observation records of the UHV transmission lines in
Guizhou Province showed that $96 \%$ of the towers were iced to varying degrees, with a maximum icing thickness of $50.78 \mathrm{~mm}$ and a maximum average icing of $15.35 \mathrm{~mm}$. The areas with severe icing were mainly concentrated in the southeastern part of Guizhou, ice-coated poles and towers accounted for $58 \%$, the highest proportion. Therefore, this article will take this process as an example to study the relationship between conductor icing and meteorological factors.

\section{Materials and Methods}

In this study, UHV transmission line poles and towers A and B in Jianhe County and Zhenyuan County, Qiandongnan, Guizhou are typical. The range study area is $108^{\circ} \sim 109^{\circ} \mathrm{E}, 26^{\circ} \sim 27^{\circ} \mathrm{N}$, as shown in figure 1 . The ice thickness and relative humidity data used in this study are from the UHV transmission line icing observation system. The temperature, wind speed, air pressure, and hourly precipitation data are from the European Centre for Medium-Range Weather Forecasts ERA5 reanalysis data, obtained by interpolation.

In order to find out the relationship between the occurrence of conductor icing and meteorological factors in this process, this paper analyzes the relationship between the icing thickness of $\mathrm{A}$ and $\mathrm{B}$ towers and the characteristics of temperature, precipitation, relative humidity, wind speed and air pressure, and calculates their correlations, and makes an analysis and comparison. 


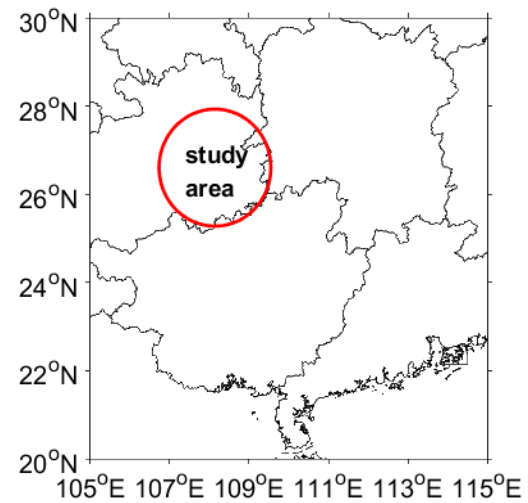

Figure 1 The study area map.

\section{Result Analysis}

\subsection{Analysis of Icing Process and Meteorological Elements}

Figure 2 shows the change of ice thickness and ambient air temperature of Tower A and B from January 24 to 29 , 2018. At 20 o'clock on January 24, 2018, the temperature dropped below $0^{\circ} \mathrm{C}$. At this time, there was no icing on Tower A. Ice coating began to appear at 3 o'clock on January 25 . At this time, the temperature had dropped to $-1.84^{\circ} \mathrm{C}$. Then as the temperature dropped, the thickness of the ice coating continued to increase, and reached the maximum thickness of $22.97 \mathrm{~mm}$ at 14:00 on the 28th. After 15:00, the temperature decreased slightly or remained, and the thickness of the ice coating remained roughly unchanged. During the icing process, the temperature was basically maintained between -7.00 and $-2.00^{\circ} \mathrm{C}$. Tower B is similar to Tower A, except for the 2-hour "DC melting" at 18:00 on the 27 th. During the icing process, the temperature was basically maintained between -8.00 and $-1.00^{\circ} \mathrm{C}$. In summary, there is a correlation between the ice thickness of the two towers and the ambient temperature. The ice thickness increases as the ambient temperature decreases. When the ambient temperature decreases to a certain range, even if the temperature does not decrease, the thickness of icing will increase due to accumulation.

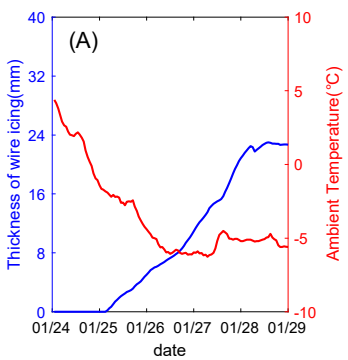

date

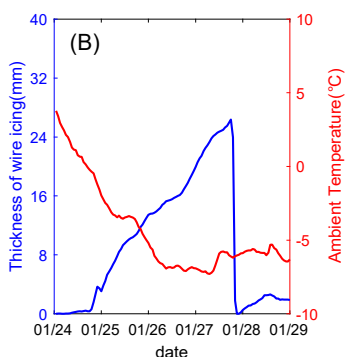

date
Figure 2 Changes in the ice thickness and ambient temperature of $\mathrm{A}$ and $\mathrm{B}$ towers.

The icing thickness and rainfall of towers A and B change with time as shown in figure 3 . As the rainfall decreases, the icing thickness continues to increase.
This is because when the rainfall is heavy, it is not easy to produce rime, and the rainfall is as small as drizzle. Sometimes it is easy to stick and produce rime adhesion, which leads to the continuous increase of the thickness of the ice coating. When the rainfall suddenly increases, the thickness of the icing decreases slightly. This is because the sudden increase in rainfall causes the icing to break. In addition, the icing observation records of UHV transmission lines in Guizhou Province show that when the rainfall is too heavy or the rainfall is zero, the increase in icing thickness is close to zero. The changes of the ice thickness and relative humidity of towers A and $\mathrm{B}$ with time are shown in figure 4 . From the data of the icing process, it can be seen that when icing occurs, the environmental humidity of both towers A and B exceeds $95 \%$. The maximum ice thickness occurs when the relative humidity reaches $100 \%$. According to statistics, there is almost no ice coating when the relative humidity is lower than $80 \%$.

Based on the above analysis, there is a correlation between the ice thickness of the two poles and the environmental water vapor conditions. Ice coating may occur only when there is weak precipitation. The thickness of the ice coating increases with the decrease of precipitation intensity.
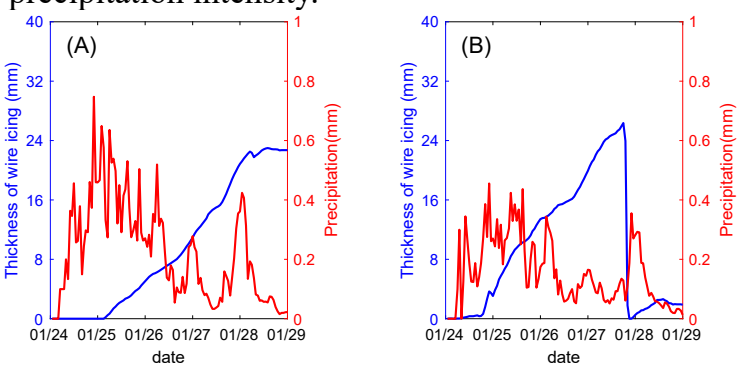

Figure 3 Changes in ice thickness and rainfall of towers A and B.
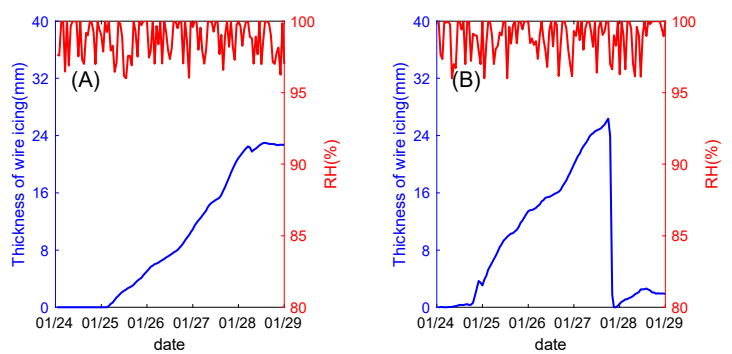

Figure 4 Changes in ice thickness and relative humidity of towers A and B.

According to statistics, during the process of icing growth, the wind speed around the towers basically fluctuates in the range of $2-6 \mathrm{~m} / \mathrm{s}$, and the wind direction is mainly northerly. In this range, as the wind speed increases, the thickness of the icing also increases with it. This is because within a certain range, as the wind speed increases, the wind blows the supercooled water droplets onto the surface of the transmission line, increasing its collision rate, the supercooled water droplets freeze on the surface of the transmission line, and the thickness of the ice coating continues to increase. When the wind speed is too high, it may cause the ice cover to break, which is not conducive to the 
growth of the ice cover. During this icing process, the ice thickness and wind speed of the A and B towers change with time as shown in figure 5 . It can be seen that during the icing growth process, the wind speed changes in the range of $2 \sim 6 \mathrm{~m} / \mathrm{s}$. In this range, changes in wind speed have a relatively small effect on the growth of icing, but they are all conducive to the growth of icing. Therefore, the thickness of the icing on the tower $\mathrm{A}$ is increasing and the thickness of the icing on the tower $\mathrm{B}$ before and after the ice melting also increases.

According to statistics, during the icing process, the air pressure has shown an increasing trend, and the air pressure is generally between 820 and 880 hpa (figure 6 ). The ice thickness of towers A and B before and after ice melting increases with the increase of air pressure. The increase in air pressure is due to the cold and high pressure crossing the border. With the strengthening of the cold high pressure, the air pressure continues to increase and the ice coating increases. After the cold high pressure crosses the border, the air pressure decreases and the ice coating intensity weakens, so that the air pressure and the ice thickness show a certain correlation $^{[9]}$.
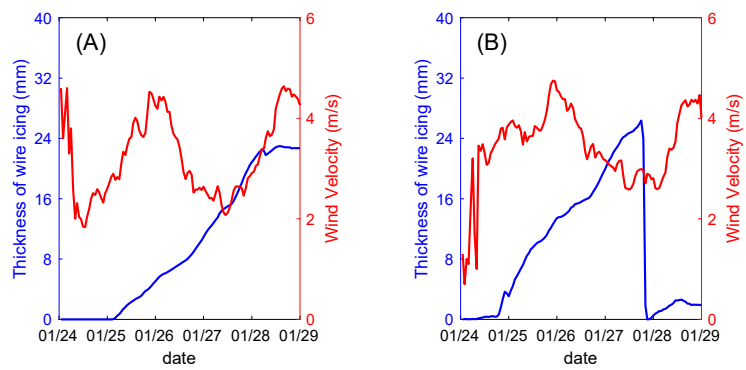

Figure 5 Changes in the ice thickness of the A and B towers and the wind speed.
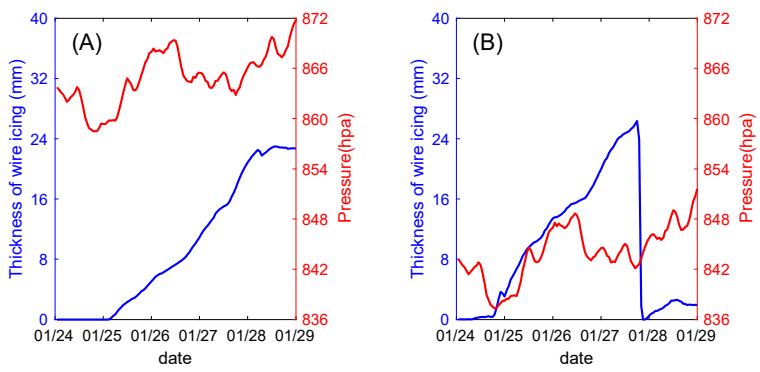

Figure 6 Changes in ice thickness and air pressure of towers $\mathrm{A}$ and $\mathrm{B}$.

\subsection{Correlation between Icing Process and Meteorological Elements}

Table 1 shows the calculated correlations between the icing of towers A and B and various meteorological elements. It can be seen that the environmental temperature has the greatest correlation with the icing of the towers, followed by the air pressure, precipitation, and the wind velocity and relative humidity have the least correlation with the icing. Among them, ambient temperature and precipitation are negatively correlated, and air pressure is positively correlated with wind velocity. Ambient temperature, air pressure, and precipitation have a good correlation with icing. Among them, ambient temperature and air pressure are significantly correlated with icing, while wind velocity and relative humidity are relatively poorly correlated with icing, and are slightly correlated. The correlation between icing on different towers and various meteorological elements is slightly different, among which the correlation with relative humidity changes greatly.

Table 1 The correlations between the icing of towers A and B and various meteorological elements.

\begin{tabular}{cccccc}
\hline $\begin{array}{c}\text { Towe } \\
\mathrm{r}\end{array}$ & $\begin{array}{c}\text { Ambient } \\
\text { temperatur } \\
\mathrm{e}\end{array}$ & $\begin{array}{c}\text { Precipitatio } \\
\mathrm{n}\end{array}$ & $\mathrm{RH}$ & $\begin{array}{c}\text { Wind } \\
\text { velocit } \\
\mathrm{y}\end{array}$ & $\begin{array}{c}\text { Air } \\
\text { pressur } \\
\mathrm{e}\end{array}$ \\
\hline $\mathrm{A}$ & -0.688 & -0.526 & -0.00 & 0.224 & 0.636 \\
$\mathrm{~B}$ & -0.900 & -0.310 & 0.115 & 0.079 & 0.541 \\
\hline
\end{tabular}

In summary, there is a certain correlation between conductor icing and a single meteorological element, indicating that there is an inevitable connection between conductor icing and environmental meteorological elements. The correlation of a single element is quite different, which means that the judgment error of icing condition by a single meteorological element is large. The increase of icing is the result of the comprehensive effect of meteorological elements, so multiple meteorological elements should be used to analyze the icing of the line.

\section{Conclusion}

The meteorological conditions for icing on the two towers $\mathrm{A}$ and $\mathrm{B}$ are that the temperature drops below $0^{\circ} \mathrm{C}$, and the temperature is $0 \sim 8^{\circ} \mathrm{C}$; there is weak rainfall, and the humidity is generally $95 \% \sim 100 \%$; the direction is northerly wind Mainly, the wind speed is generally $2 \sim 6 \mathrm{~m} / \mathrm{s}$; the air pressure rises, generally in the range of $820 \mathrm{hpa} ~ 880 \mathrm{hpa}$. The meteorological elements that are more relevant to the icing of towers A and B are environmental temperature, air pressure, and precipitation in order, and less relevant to wind velocity and relative humidity. Multiple meteorological elements should be used to analyze the line icing.

This article is only a case analysis of a continuous icing process on the Qiandongnan transmission line in 2018, which has important guiding significance for the power sector to prevent conductor icing disasters and ensure power safety. In addition to the meteorological factors given in the article, the influencing factors of icing thickness are also closely related to altitude, mountain topography, and pass direction. These issues will be analyzed and discussed in detail in future studies.

\section{Project}

${ }^{1}$ China Southern Power Grid Science and Technology Project "Research on Numerical Prediction Technology of Transmission Line Ice Coating under Micro-terrain 
Conditions"

${ }^{2}$ China Southern Power Grid Science and Technology Project "Research and Application Project of Comprehensive Meteorological Service Platform for Main Grid for West-to-East Power Transmission-Meteorological Data Analysis Technical Service"

\section{References:}

1. Yin H and Wang J J 2017 High Voltage Apparatus 53(12) 0145-50

2. Zhang $\mathrm{J} \mathrm{T}$, Li $\mathrm{C}$, Zhao $\mathrm{Z} \mathrm{G}$ and Zhang $\mathrm{J} \mathrm{H}$ 2018 Computer Engineering \& Software 39(02) 16-21

3. Huang X B, Sun Q D, Zhang G J, and Ma J G 2008 High Voltage Apparatus 44(4) 289-94
4. Huang H H, Song L L, Qin P, Liu A J and Jiang C L 2010 Journal of Tropical Meteorology 26(1) 7-12

5. Hu Y N Analysis of the weather conditions and numerical simulation for high-voltage wire icing cases 2016 Nanjing University of Information Science and Technology

6. Ouyang L S and Huang X B 2011 High Voltage Apparatus 47(3) 31-6

7. Tao Y, Wu X L, Duan X, He H and Wang M 2009 Journal of Catastrophology 24(2) 82-6

8. Qin W, Luo X L, Zheng F Q, Zhong L H, Zhou S Y and Su Z 2019 Desert and Oasis Meteorology 13(1) $110-6$

9. Yue Y S and Wang L 2020 Popular Utilization of Electricity 35(10) 26-28 